\title{
A Study on the Role of Precision Agriculture in Agro-Industry
}

\author{
Siddegowda C. J. 1 \& A. Jayanthila Devi ${ }^{2}$ \\ ${ }^{1}$ Research Scholar, College of Computer Science and Information Science, Srinivas \\ University, Mangalore, Karnataka, India and Assistant Professor, Dept. of Computer Science, \\ Vivekananda Institute of Management, Bengaluru, Karnataka, India \\ ORC ID: 0000-0001-8206-9367; E-mail: siddegowdacj@gmail.com \\ ${ }^{2}$ Professor, College of Computer Science \& Information Science, Srinivas University, \\ Mangalore - 575001, India. \\ ORCID: 0000-0002-6023-3899; Email: jayanthilamca@gmail.com
}

Subject Area: Business Management.

Type of the Paper: Research Paper.

Type of Review: Peer Reviewed as per $|\mathrm{C}| \mathrm{O}|\mathrm{P}| \mathrm{E} \mid$ guidance.

Indexed In: OpenAIRE.

DOI: https://doi.org/10.5281/zenodo.5502329

Google Scholar Citation: IJAEML

\section{How to Cite this Paper:}

Siddegowda, C. J., \& Jayanthila Devi, A., (2021). A Study on the Role of Precision Agriculture in Agro-Industry. International Journal of Applied Engineering and Management Letters (IJAEML), 5(2), 57-67. DOI: $\underline{\text { https://doi.org/10.5281/zenodo.5502329 }}$

International Journal of Applied Engineering and Management Letters (IJAEML) A Refereed International Journal of Srinivas University, India.

Crossref DOI : https://doi.org/10.47992/IJAEML.2581.7000.0103

(C) With Authors.

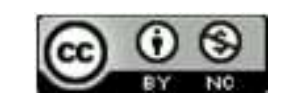

This work is licensed under a Creative Commons Attribution-Non-Commercial 4.0 International License subject to proper citation to the publication source of the work.

Disclaimer: The scholarly papers as reviewed and published by the Srinivas Publications (S.P.), India are the views and opinions of their respective authors and are not the views or opinions of the S.P. The S.P. disclaims of any harm or loss caused due to the published content to any party. 


\title{
A Study on the Role of Precision Agriculture in Agro- Industry
}

\author{
Siddegowda C. J. ${ }^{1}$ \& A. Jayanthila Devi ${ }^{2}$ \\ ${ }^{1}$ Research Scholar, College of Computer Science and Information Science, Srinivas \\ University, Mangalore, Karnataka, India and Assistant Professor, Dept. of Computer Science, \\ Vivekananda Institute of Management, Bengaluru, Karnataka, India \\ ORC ID: 0000-0001-8206-9367; E-mail: siddegowdacj@ gmail.com \\ ${ }^{2}$ Professor, College of Computer Science \& Information Science, Srinivas University, \\ Mangalore - 575001, India. \\ ORCID: 0000-0002-6023-3899; Email: jayanthilamca@gmail.com
}

\begin{abstract}
Purpose: Agriculture is a vast field that necessitates the assistance of disciplines from other fields in order to properly grow. In recent days Information technology is been used in agriculture that helps in the efficiency of the growth of the productivity of agriculture such as in the development of the quality of the farming and its products Precision agriculture are used to increase the growth of the crop quantity. In this paper, a survey includes the analysis and application of precision agriculture. Precision agriculture is used to increase the growth of the crop quantity. And various Precision agriculture companies that have helped the farmer in the field growth.
\end{abstract}

Objectives: To study the role of Information Technology used in Agriculture, and view on various techniques used in precision agriculture.

Methodology/Design/Approach: The analysis and the application of precision agriculture are done by referring various research paper, articles. A Literature Survey is done.

Findings/Result: Farmers are currently hesitant to use the new Techniques, when compared to traditional farming, Precision farming has the potential to produce higher yields.

Originality/value: Based on the secondary data available, the paper focus on the application of precision agriculture.

Findings/Result: To study the role of Information Technology used in Agriculture, Precision Agriculture.

Keywords: Precision Agriculture, Precision Agronomics, Information Technology, Remote sensors.

\section{INTRODUCTION :}

Agriculture is a huge industry that is critical to modern man's survival. Plants are the food chain's producers, and the life cycle would be impossible without them. Agriculture is a vast field that necessitates the assistance of disciplines from other fields in order to properly grow. Economics, management, and technology are examples of disciplines that play an important role in the sector.

Information technology and agriculture seemed to be two different distinct fields but now everything has been changed. Nowadays Information technology is been used in agriculture that helps in the efficiency of the growth of the productivity of agriculture such as In the development of the quality of the farming and its products.

\section{OBJECTIVES :}

- To study and analyze the role of information technology in agriculture.

- To understand the Case study on how precision agriculture is used in argo-companies.

- To Analysis of the application in precision agriculture.

- To understand precision ergonomics. 


\section{METHODOLOGY :}

The information is collected from various sources such as journals, articles, and in some blogs. The analysis and the application of precision agriculture are done by referring various research papers, articles.

\section{PRECISION AGRONOMICS :}

Precision agronomics is a word that refers to the use of technology in connection with methods. At its core, it's all about providing more accurate agricultural practices for planting and producing commodities [1].

\subsection{Variable-rate technology}

VRT refers to any technology that allows for a variable input program that allows farmers to adjust the amount of inputs applied in a specific location. Farmers can manage the number of seeds, fertilizers, insecticides, and water they use with variable-rate technology. It optimizes planting density and increases the effectiveness of pesticide and nutrient application rates, lowering farm costs and, most significantly, lowering negative environmental impact. It has the power to enhance input efficiency, field profitability, and environmental responsibility [2]. The key components of this technology are a system, programs, a sensor, and a differential global positioning system (DGPS).

\subsection{GPS soil sampling}

Soil testing discloses data such as $\mathrm{pH}$ level and nutrition value that are essential for making wellinformed decisions. Farmers are helped By Soil sampling to determine by taking the discussion in the production. Data from data gathering and in checking the sample that are been used as the input for the programs to deterring sowing and fertilizer optimization [3]. Global Positioning System (GPS)helps in navigating the location without any practical checking distance

\subsection{Computer-based applications}

Crop plantation, location of the crops, and the location of the farm all can be created with computer tools. This leads to the development of precision apps. That app is benefited farmers to use it and also leads to reducing the financial amount, raising crop production. The only difficulties with these apps as it prevents in taking a larger farm decision, even though with the help of the expert

\subsection{Remote sensing technology}

Agriculture has been using remote sensing technology since the late 1960s [4]. For the purpose of observing and specifying land, water, and other natural resources this can be a beneficial tool. this may help with everything from determining what elements are affecting a crop at a given time to measuring how much moisture is in the soil [5]. Drones and satellites are used to collect the data that in return helps the farmer to take the decision for the farm which is beneficial [6].

\section{LITERATURE REVIEW :}

Zhang [7] images are used in the replacement of the satellite imagery since the cost of the product operation is high, that are used in Precision agriculture. Remote sensing applications are used in monitoring the field, chemical analysis, crop management utilizing satellites' high-resolution cameras. Islam T. Almalkawi [8] explained in detail about the wireless multimedia sensor networks and proposed an algorithm and protocols and also discussed about the challenges faced during designing the architecture and also come across solutions for the existing WMSM at the various layers of the communication stack, including physical, MAC, routing, transport, and application, as well as crosslayer implementation.

Aubert [9] aims at discussing the acceptance of PA technology, as well as the various justifications for investing in different types of PA techniques. Despite its good effects, the study reveals that PA technology adoption remains limited. The essay attempts to explain why there is such a low rate of adoption. The authors find that a variety of factors contribute to many farmers' lack of adoption, 
including a lack of local standards and a lack of collaboration among stakeholders. To achieve effective communication, standards are required.

Marvin T. Batte [10] found that precision farming (PF) has the capacity to assist farmers in making better input decisions based, perhaps cutting production costs or increasing outputs, and so improving profitability. Hence Farmers use PF to for good benefits and costs on individual farms. To visualize the findings, the authors conducted a case study of six early adoptive farmers, followed by a cross-case summary. According to the authors, the application of PA has aided all six farms. to help them grow their business The case farm management was split on whether or not the although the PA system as a whole was profitable, everyone agreed that they would continue to adopt new PA systems.

Mark Brady [11] the goal of this research was to assess the scheme's relative cost-effectiveness and to examine the implications of agriculture policy for the lowest-cost solution. The model was created to determine how the Swedish nitrogen abatement scheme affects crop farms in southern Sweden, as well as how this relates to coastal nitrogen load. When developing the precision agricultural optimization issue, Brady's model is utilized as an example.

Diederen [12] studied the adoption of innovations in the agriculture industry, as well as the behavior that guides adoption decisions, were investigated. The authors claim that the advantage of their method is that the results are more reliable when they are not tied to a specific breakthrough The primary focus of the research is on the search for, handling, and exchange of knowledge about innovations under the ideal market situation. And explain about the reason of using different techniques by the adopters vary from different criteria such as scale, business strategy, age, and solvency.

Fountas [13] discussed about the designation of the systems-based model to describe farmers' decisionmaking processes in data activities, as well as its validation in Precision Agriculture. To describe a farm manager's decision-making process, twenty-one decision-analysis elements were developed. The information flows from data to decision were then described using a general data flow diagram (DFD). The designed model was demonstrated in different university and concluded that its adaptable enough to accommodate different farm management plans and practices. It aided farm managers in organizing their decision-making processes and thinking more rationally.

Lawes [14] designed a model known as the economic optimization model to analyze VRT. This model is applied to 20 crops with different cost and nutrient levels, the showed that only a third of the fields in our study achieved a significant return from VRT. The number of areas that will benefit from VRT is influenced by commodity and input prices, but these factors are uncontrollable.

Salam A [15] discussed about the barrier in adoption in Digital agriculture technology and solutions that are currently more expensive than the benefits they provide. Secondly, the concentration is given to the farmer who have bigger farm the lower farm is neglected. Data collection are done using this technology but the result takes a long period of time hence is waste lots of time of the farmers

Shepherd M [16] showed that usage of digital technologies in agriculture has proved the ability to increase in the production of commodities, food that can benefit the farmers. considering marketing agriculture as the use of extensive digital data to support agricultural decision-making across the whole agricultural value chain, not only on farms or in production. It encompasses the application of "big data" to generate actionable information. As a result, it provides "the potential for a "nearly direct contact" between the customer and the food provider. They also recognize that integrating digital agriculture and equitably distributing its potential benefits will necessitate considerable agricultural system adjustments as well as the resolution of critical socio-ethical and technical concerns.

James Mintert [17] studied the usage of information technology in agriculture has brought a huge difference in production, the quality, and the time spends overproduction. and also discussed the space between new technologies that are used in agriculture for better performance. New technology is enforced in some particular field, such as in sensors, and mapping [18]. Usage of technology as performed better in the animal in the usage of a resource to maintain the quality of the food product. Precision agriculture helps in the analysis of the food supply chain as well as the control of both quantity and quality of the production of food [19]. Uferah Shafi [20] proposed a model for analyzing crop growth, the model has two methods in the first method uses a wireless sensor network to determine the yield health condition, and the second method, it uses remote sensing to determining the condition of the crop whether it is healthy or not. 


\section{ROLE OF AGRICULTURE IN IT :}

Information Technology in Agriculture is popular in Recent days, IT helps in passing the information among the farmers about the yield-related inquiries, such as yield protection and crop production. Modern farming approaches such as satellite farming have already begun to gain favour in other nations; [21] this precision farming makes direct contributions to increasing crop productivity through the use of technology. Space technology, GIS, sensing, agronomic and soil science methods, and so on are all examples, can that be used to boost the growth of agriculture, particularly in broad areas where this method is both cost-effective and practical. This competing technological aid has begun to be implemented by large food chain shops over their huge regions.

However, in India, the potential of IT in the agricultural industry appears to be underutilized. A key stumbling block is a lack of understanding of the technologies. Farmers in India are currently hesitant to break free from the shackles of traditional input sources. In today's world, using knowledge is not only beneficial but also necessary. According to studies, the adoption of current technologies can make a significant difference.

\subsection{Farmers' Decision Support System (DSS):}

The decision is taken by farmers so they need to be careful since that can lead to any problems so the decision should be made wisely. Exports will be more competitive as a result of the WTO's refined exporting rules. The market value of the commodities is determined by the overall cost of the crop, the techniques implemented in farming.[23] farmers are benefited by using this type of data to determine the economic conditions.

\subsection{Monitor the market:}

Changes in global trade will have an impact on Indian trade hence it's important to be careful about the shocks. And monitor the market has to be done to assist the farmers to make the decision that can help in financial loss [24].

\subsection{Chances/opportunity:}

Farmers should increase the opportunities in order to increase the business in the yield production [25]. Farmers in India should use the chance and take advantage of it. The company has to come up with new technologies to beat the competition. Overall, the industry of the agriculture is coming the revolution and fortunately, both the federal and state governments are well aware of the situation. As a result, a variety of public awareness campaigns are underway.

\subsection{Increases in productivity:}

The data are collected from various new field such as climate conditions, production of the farm methods, and yield improvement. Regardless of their agro-ecological region, information technology plays a critical role in ensuring that farmers have access to this information. Farmers in Africa can read what farmers in other parts of the world are doing because to technology. Farmers enhance their farming abilities as a result of this obtained information, resulting in improved farming and higher yields [26].

\subsection{Participation of the community:}

Several activities have been made possible by IT applications, and community involvement in agriculture has also increased. The output of local items can be boosted when a community embraces modern agricultural methods. In few regions, people benefit immensely from the land and resources available for agriculture, and with IT, local farmers can work together more effectively, resulting in increased production and income for everyone.

\subsection{Farm produce value addition and good post-harvest procedures:}

Most farmers gain a lot of crop yields after harvesting due to effective crop cultivation, but they lose money due to improper storage a few months later [27]. However, in some areas of the country, this is not the case in developed countries with well-established storage infrastructure. Information Technology leads the farmers to know the concept of post-harvest and the other method of storage that are 
implemented in other nation. They can then study and apply these strategies to their own crops, reducing crop losses.

\subsection{The farmer's decision-making abilities have enhanced:}

Information Technology have led in the developing of the records of the crop and also in the proceeding with the everyday activities. This has been helped the farmer to making the decision about the sorts of fertilizers to use, the seeds to plant, when to market his or her produce, and how to apply the most effective farming techniques.

\subsection{At the field, productivity and service delivery has improved:}

With the use of information technology, crop data, animal data, and any other farm data can be generated and maintained considerably more easily than with traditional operations. The data that are generated in the agricultural farm are gathered and maintained considerably more easily than with traditional operations. Self-operating agriculture machinery are designed to execute the work such as watering or spraying even when the farmer is not there, resulting in very efficient service delivery.

\subsection{Climate-smart agriculture and weather prediction:}

In farming, the weather and environment are extremely important [28]. A weather analyzing system is a vital tool for monitoring a farm's climatic circumstances since a better understanding of the surrounding weather conditions helps solve many of the farm's difficulties. Farmers may obtain weather forecasts thanks to IT infrastructure, which allows them to plan when to irrigate or plant, as well as how much water to use for irrigation. This is extremely important in agricultural output.

\subsection{GPS position and remote sensing :}

This is really important in farming. The location of a farm is critical since it determines the kind of seed to use, the quantity of irrigation to utilise, and, most importantly, the type of crop to plant [29]. It is easier to locate a farm, even if it is kilometres distant, thanks to the usage of technology [30]. This new technology has made the farmer more feasible, specifically, GPS global positioning system helped the farmers to to classify the different places into different agro ecological zones.

\section{PRECISION AGRICULTURE COMPANY :}

The world's leading precision agriculture companies are driving enormous growth and innovation in the precision agriculture market. Digital agriculture is known as collecting the data in the digitalized manner, saving those data to analyse for further use. Precision agriculture are referred as new technology farming method for the crop management for to crop variability both within and between fields [21].

\subsection{Mothive:}

Mothive is ranked first in the precision agriculture company. Mothive is an automated agronomy service that assists farmers in increasing efficiency, reducing waste, and improving crop predictability. Crop monitoring is one of Mothive's precision agriculture specialties, with devices positioned close to the plants collecting environmental and soil data. Crop growth conditions, illnesses, and crop harvest are all predicted using Mothive's bespoke machine learning models. Mothive has demonstrated a 21 percent boost in yield thanks to its excellent agriculture technology.

\subsection{Cropx:}

CropX comes in second in the precision agriculture company. CropX has been leading company in determining the soil and agriculture sensors. Farmers are able to understand the usage the water throughout the entire crop.

\subsection{Arable:}

Arable comes in third place in precision agriculture company. Arable Labs, are best in making the decision in agriculture, creates low-cost technologies that assist people in collecting and analyzing sitespecific agricultural data. Arable is an in-field measurement-based agricultural business intelligence 
tool. With Measurements that Matter, Arable helps in the decision of the agriculture are information and other one is based on natural resource based.

\subsection{Ceres Imaging:}

Ceres Imaging is ranked \#4 in precision agriculture company. Ceres Imaging are used to help the farmers in interpreting, also in utilizing their information to design and construct successful and long-term enterprises. Farmers and agribusinesses are served by the corporation, which is situated in California and provides airborne spectral images and analytics. In United states and in Australia Ceres Imaging develops a imagery-based technologies using new designed algorithms, sensors that are used in the farms that are helped for the farmers. Customers are able to identify any infection in the farm or any other problem before a week they present in the farm that are able to see from the human eye.

\subsection{AgriSync:}

AgriSync is ranked 5th in the precision agriculture company. In industries like agricultural production, farmed animals, and architecture, the AgriSync platform lets teams better service consumers and support goods. AgriSync is a mobile agricultural support platform that focuses on farmers and their collaboration for better farming. AgriSync uses artificial intelligence, data exhaust, and an intuitive software user experience to make sure that has biggest impact on it.

\subsection{Gamaya:}

Gamaya is ranked 6th in the precision agriculture company. Gamaya delivers precision agricultural technologies for large-scale crop monitoring and diagnostics. For Gamaya's farmland analytics services uses, machine learning, designation of the drone and latest spectral imaging are developed. Gamaya agriculture analytics increases the product efficiency that leads to the decision making easier, it uses chemicals and pesticides that are helped in increasing the production of the farming, and also reducing the environmental effect.

\subsection{Precision Planting:}

Precision Planting is ranked 7th in the precision agriculture company in the world. Precision Planting is where will find innovative ideas and cutting-edge technology to assist and determine the depth, gaps in between to achieve the goal.

\subsection{AgEagle:}

AgEagle is ranked eighth. Precision farming is AgEagle's are used for information collection and coming with the better solution that helps farmers in obtaining more production, spending least amount of time in the field, more profits, least crop damage, increasing in the efficiency. AgEagle designed a technology using map-based that can guide the farmers for agricultural growth.

\subsection{PrecisionHawk:}

PrecisionHawk is ranked 9th in the precision agriculture company. remote sensing applications and data processing services are presented by the PrecisionHawk for drones and unmanned aerial vehicles (UAVs). That are implemented in the agriculture, and telecommunications industries. Drones and information are use in the PrecisionHawk to specializes in commercial use.

\subsection{Aker Technologies:}

Aker Technologies completes BizVibe's top 10 precision agriculture firms list. Aker Technologies are designed to determining the crop technologies that help the farmer for the sooner growth of the crop, precision farming. Inside the canopy of crop fields, Aker consists of a unique sensor, computer vision, and a program that are able to identify the disinfected crop and fertility.

\section{APPLICATION IN PRECISION AGRICULTURE :}

\subsection{AgroPad:}

AL application AgroPad are able to determine the soil and water in the farm thus this application helped the farmer a lot. The AgroPad is a little paper gadget similar to the size of a business card [31]. When a drop of water or soil is placed on the AgroPad, and chemical analysis is performed by a "microfluidic 
chip" that is inside the card. A series of colorimetric tests are done on the back of the card, with each circle representing a unique chemical analysis. the color of each circle signifies the amount of a certain chemical in the sample. Using a smartphone and a dedicated mobile application, the farmer may take a single snapshot of the AgroPad and receive an instant chemical test result for a water sample. A dedicated mobile app scans the card and provides instant chemical analysis to the farmer.

\subsection{Plantix:}

Plantix is a mobile application that contains a large collection of plant disease images that can be compared [32]. PEAT's mission is used by the farmers almost all part of the world in order to increase the growth of the agriculture and also giving the best treatment in the identification of the crop disease precisely. Thus, in order it helps in determining, and giving the best treatment based on the situation. Many farmers in India are adopting this service, which requires only an image of the sick leaf to be submitted to the Plantix WhatsApp number, and the diagnosis is messaged back to the sender over WhatsApp in real time.

\subsection{Trringo and EM3:}

The successfully duplicated the uberization of renting farm machinery and tractors in India, earning the moniker "ubers of agriculture." Farmers can hire their essential agricultural machinery on a pay-per-use basis through their services, which can be accessed via a mobile application or a phone call, saving them time and assuring affordable pricing while decreasing uncertainty about availability [33]. EM3, we're breaking preconceptions by bringing innovation and mechanization to the farming community on a Payfor-Use basis, enhancing agricultural output. This method has a significant impact on agricultural viability. To integrate and strengthen the value proposition, the power of information technology, mobile telecom services, financial services, and other services are used. EM3 refers to their software as Samadhan (Hindi for Solution) and is classified as Farming as a Service (FaaS), which establishes an application that enables the connection between the farmers and farms in an efficient and cost-effective manner through a network of farm centers.

\subsection{Use of drones to fight locusts in India:}

Since the winter months of 2019, locusts have been attacking 15 and destroying significant swaths of India's crops on a regular basis, and the attack is still going on. [34] Drones have been used for antilocust spraying by the Agriculture Ministries at both the federal and state levels. They are proving to be an effective solution in an otherwise difficult situation in which India is dealing with large-scale agricultural losses in Rajasthan, Gujarat, Madhya Pradesh, and Uttar Pradesh.

\subsection{AgNEXT:}

AgNext has created a full-stack integrated algorithms, software, and hardware platform that handles quality assessment challenges across the agri value chain, allowing businesses to analyse food on-thefly in less than 30 seconds [35]. It's a platform for integrating rapid quality assessments in the agriculture and food value chain by combining hardware, software, and data analytics with AI-based spectral and AI-based picture analytics. Thus, they claim that their solution, which uses a small pocket-sized gadget, can detect the chemical and physical composition of grains such as wheat, rice, pulses, maize, and oilseeds in less than a minute. The chemical composition of milk and honey can be identified using the same Bluetooth enabled, battery-operated hand-held equipment that works in tandem with a mobile application.

\subsection{Ergos:}

In the Agri-tech scene, Ergos offers one of the most unusual models. They have a "Grain Bank model" that allows small and marginal farmers able to access the post-harvest solutions. This helps the farmer in converting all the crops into a digital amount thus with the help of Banks able to get amount based on the crops harvest. Thus, Ergos helps the farmer in getting a good amount for the product they harvest. Farmers can store and withdraw a single bag of grains using the Ergos approach. Farmers benefit from rapid liquidity and increased profitability because they are not forced to sell all of their produce at once at market pricing during harvest season. They currently provide the following services to farmers at the farmgate through efficient use of technology and direct farmer contact [36]. 


\subsection{Yuktix:}

Yuktix Technologies is a Bangalore-based Agritech business that focuses on developing digital solutions for farmers. Farm monitoring and risk management are important aspects of agriculture. Growers can use the solution to make better judgments. And put in place best practices that will boost yield while reducing losses. Growers may use the solution to make better decisions and apply best practices that will boost productivity and reduce losses. The tools are powered by their GreenSense IoT devices and GreenSense dashboard hardware and software solution. Yuktix GreenSense is an agricultural off-grid remote monitoring and analytics technology. Growers may utilize the solution to make better decisions and implement best practices that will increase productivity while lowering losses. GreenSense IoT devices and the GreenSense dashboard hardware and software solution power the tools. Yuktix GreenSense is an off-grid agricultural remote monitoring and analytics system.

\section{THE FUTURE OF AGRICULTURE WITH IT :}

As previously stated, effective software solutions can be developed using information technology to address the demands of Indian farmers. Efficient web tools and communications protocols can ensure the availability of these types of technologies. The collection of the entire range of application packages and databases is required to complete the work. Agriculture is a mixture of many little locations, needing an ocean of data inputs; combining all of this data is a large process. As a result, the most feasible choice is to develop technical solutions personalized. It is advisable that the system design be framed only after thoroughly reviewing the problem; we must depart from the usual way of developing the system first and then adding inputs in order to achieve realistic outcomes. Only once all of the data has been documented to a single platform can a complete system be built. It is possible to monitor an effective agricultural display using remote sensing and GIS tools. Crop stress, soil issues, obstacles, natural disasters, and other issues can all be addressed efficiently with this technique. Precision farming's export potential can be skewed in our country's advantage if it is motivated to cover enormous swaths of land. New technology will continue to emerge as farmers adopt precision agriculture. Artificial intelligence will be the next significant step forward. While AI will never be able to mimic the types of complicated judgments that farmers must make on a daily basis, it may be able to assist in making those decisions easier. Farmers today have access to a variety of information. They have so much data that they don't know what to do with it. AI is capable of assessing large volumes of data in a short amount of time and recommending the best course of action. This data may then be used to predict the ideal time to plant, predict pest and disease outbreaks before they happen, and provide in-field inventory management that could predict yields before harvest.

\section{CONCLUSION :}

As a result, it can be stated that information technology is an important aspect of farming and should be fully embraced; we need to move away from the local and traditional agricultural methods. When compared to traditional farming, IT integrated farming has the potential to produce higher yields. Many new technologies for farming have been developed in recent decades, ranging from the worldwide navigation system to numerous sensors for measuring soil and crop conditions. Precision Agriculture have helped the farmer in getting a good amount of the crop compared with the normal way, and the amount of expenditure are also reduced by following this new technology. Furthermore, precision farming, which is based entirely on data, can boost yields and enhance crop quality while also conserving the environment. This new technique has a bright future, especially because it adds to every farmer's most crucial goal.

\section{REFERENCE :}

[1] https://agfundernews.com/what-is-precision-agriculture.

[2] Sawyer, J. E. (1994). Concepts of variable rate technology with considerations for fertilizer application. Journal of Production Agriculture, 7(2), 195-201.

[3] Wollenhaupt, N. C., \& Wolkowski, R. P. (1994). Grid soil sampling. Better crops, 78(4), 6-9. 
[4] Liaghat, S., \& Balasundram, S. K. (2010). A review: The role of remote sensing in precision agriculture. American journal of agricultural and biological sciences, 5(1), 50-55.

[5] Shanmugapriya, P., Rathika, S., Ramesh, T., \& Janaki, P. (2019). Applications of remote sensing in agriculture-A Review. International Journal of Current Microbiology and Applied Sciences, 8(1), 22702283.

[6] Mogili, U. R., \& Deepak, B. B. V. L. (2018). Review on application of drone systems in precision agriculture. Procedia computer science, 133, 502-509.

[7] Zhang, C., \& Kovacs, J. M. (2012). The application of small unmanned aerial systems for precision agriculture: a review. Precision agriculture, 13(6), 693-712.

[8] Almalkawi, I. T., Guerrero Zapata, M., Al-Karaki, J. N., \& Morillo-Pozo, J. (2010). Wireless multimedia sensor networks: current trends and future directions. Sensors, 10(7), 6662-6717.

[9] Aubert, B. A., Schroeder, A., \& Grimaudo, J. (2012). IT as enabler of sustainable farming: An empirical analysis of farmers' adoption decision of precision agriculture technology. Decision support systems, 54(1), 510-520.

[10] Batte, M. T., \& Arnholt, M. W. (2003). Precision farming adoption and use in Ohio: case studies of six leading-edge adopters. Computers and electronics in agriculture, 38(2), 125-139.

[11] Brady, M. (2003). The relative cost-efficiency of arable nitrogen management in Sweden. Ecological Economics, 47(1), 53-70.

[12] Diederen, P., Van Meijl, H., Wolters, A., \& Bijak, K. (2003). Innovation adoption in agriculture: innovators, early adopters and laggards. Cahiers d'Economie et de Sociologie Rurales, 67, 29-50.

[13] Fountas, S., Wulfsohn, D., Blackmore, B. S., Jacobsen, H. L., \& Pedersen, S. M. (2006). A model of decision-making and information flows for information-intensive agriculture. Agricultural Systems, 87(2), 192-210.

[14] Lawes, R. A., \& Robertson, M. J. (2011). Whole farm implications on the application of variable rate technology to every cropped field. Field Crops Research, 124(2), 142-148.

[15] Salam, A. (2020). Internet of things for environmental sustainability and climate change. In Internet of Things for Sustainable Community Development, 33-69. Springer, Cham.

[16] Shepherd, M., Turner, J. A., Small, B., \& Wheeler, D. (2020). Priorities for science to overcome hurdles thwarting the full promise of the 'digital agriculture' revolution. Journal of the Science of Food and Agriculture, 100(14), 5083-5092.

[17] Stafford, J. V. (2000). Implementing precision agriculture in the 21st century. Journal of agricultural engineering research, 76(3), 267-275.

[18] Gebbers, R., \& Adamchuk, V. I. (2010). Precision agriculture and food security. Science, 327(5967), 828-831.

[19] Shafi, U., Mumtaz, R., García-Nieto, J., Hassan, S. A., Zaidi, S. A. R., \& Iqbal, N. (2019). Precision agriculture techniques and practices: From considerations to applications. Sensors, 19(17), 3796.

[20] Brisco, B., Brown, R. J., Hirose, T., McNairn, H., \& Staenz, K. (1998). Precision agriculture and the role of remote sensing: a review. Canadian Journal of Remote Sensing, 24(3), 315-327.

[21] Mittal, S. C. (2001). Role of information technology in agriculture and its scope in India. Fertiliser News, 46(12), 83-88.

[22] Taechatanasat, P., \& Armstrong, L. (2014). Decision support system data for farmer decision making.

[23] Raj, S., \& Darekar, A. Farming 2.0: Digitising Agri Value Chain.

[24] Daberkow, S. G., \& McBride, W. D. (1999, January). Adoption of precision agriculture technologies by US corn producers. In Proceedings of the Fourth International Conference on Precision 
Agriculture (1821-1831). Madison, WI, USA: American Society of Agronomy, Crop Science Society of America, Soil Science Society of America.

[25] Buman, T. (2013). Opportunity now: integrate conservation with precision agriculture. Journal of soil and water conservation, 68(4), 96A-98A.

[26] Whelan, B., \& Taylor, J. (2013). Precision agriculture for grain production systems. Csiro publishing.

[27] Koenig, K., Höfle, B., Hämmerle, M., Jarmer, T., Siegmann, B., \& Lilienthal, H. (2015). Comparative classification analysis of post-harvest growth detection from terrestrial LiDAR point clouds in precision agriculture. ISPRS Journal of Photogrammetry and Remote Sensing, 104, 112-125.

[28] Tenzin, S., Siyang, S., Pobkrut, T., \& Kerdcharoen, T. (2017, February). Low-cost weather station for climate-smart agriculture. In 2017 9th international conference on knowledge and smart technology (KST) (172-177). IEEE.

[29] Khanal, S., Fulton, J., \& Shearer, S. (2017). An overview of current and potential applications of thermal remote sensing in precision agriculture. Computers and Electronics in Agriculture, 139(1), 2232.

[30] Yousefi, M. R., \& Razdari, A. M. (2015). Application of GIS and GPS in precision agriculture (a review). International journal of advanced Biological and Biomedical Research, 3(1), 7-9.

[31] Raj, S., \& Darekar, A. Farming 2.0: Digitising Agri Value Chain.

[32] Mehla, M. K. (2020). Applications of Smartphone Sen-sors in Agriculture.

[33] Sarangi, S. K. (2018). Digital farming: the beacon of new age agriculture for feeding billons in India. IOSR J Bus Manage, 20(1), 54-63.

[34] Daponte, P., De Vito, L., Glielmo, L., Iannelli, L., Liuzza, D., Picariello, F., \& Silano, G. (2019, May). A review on the use of drones for precision agriculture. In IOP Conference Series: Earth and Environmental Science. 275(1), p. 012022. IOP Publishing.

[35] Sarangi, S. K. (2018). Digital farming: the beacon of new age agriculture for feeding billons in India. IOSR J Bus Manage, 20(1), 54-63.

[36] Beriya, A. (2020). Digital agriculture: Challenges and possibilities in India. ICT India Working Paper, 35(1), 1-11. 